\title{
A Study on the Knowledge, Attitude, and Practices of Iranian Mothers towards Childhood Obesity
}

\author{
Mahmood Karimy ${ }^{a} \quad$ Bahram Armoon $^{b} \quad$ Neda Fayazic \\ Hamid Reza Koohestani ${ }^{a}$ \\ aSocial Determinants of Health Research Center, Saveh University of Medical Sciences, \\ Saveh, Iran; ${ }^{b}$ Department of Public Health, Faculty of Health, Saveh University of Medical \\ Sciences, Saveh, Iran; 'Department of Nursing, Faculty of Nursing, Saveh University of \\ Medical Sciences, Saveh, Iran
}

\section{Keywords}

Knowledge $\cdot$ Attitude $\cdot$ Behavior $\cdot$ Childhood obesity

\section{Abstract}

Objectives: In the recent decades, a dramatic increase in childhood obesity is one of the main public health problems. The aim of the study was to assess the knowledge, attitude, and practices (KAP) of Iranian mothers towards childhood obesity. Methods: This cross-sectional descriptive research was conducted on KAP of 432 mothers and their children aged 6-7 years ( 214 boys and 218 girls) who were referred to the Zarandieh health centers, Iran, in 2017. The participants were selected via multistage random sampling. Demographic and KAP data were obtained by self-report using standard questionnaires. The weight and height of the subjects were measured according to standard methods and body mass index was calculated. Data were analyzed by inferential statistics using SPSS18 software. Results: The prevalence of obesity (OB) was $11.5 \%$ in boys and $7 \%$ in girls. The mean score for attitude for mothers with normal-weight children was higher than for mothers with obese children. Food habits like consumption of breakfast, having fast food at least twice a week, and eating in front of TV were associated with OB. Physical activity habits like duration of TV watching/computer games/sleep and regular physical exercise were associated with OB. Conclusions: This study identified the importance of educating Iranian mothers to change of lifestyle (eating and physical activity habits) and attitudes towards weight control in their children. Therefore, it seems that these results may be valuable in the development of educational programs and strategies for the prevention of childhood obesity. 
Karimy et al.: Knowledge, Attitude, and Practices of Iranian Mothers towards Childhood OW/OB

\section{Introduction}

The sudden increase of childhood overweight and obesity (OW/OB) in both developed and developing countries is now a public health problem [1]. According to the definition of obesity, children with body mass index (BMI) above the 95th percentile (considering age and gender) are categorized as obese, and those with BMI between 85 and 95 are categorized as overweight [2,3]. The review study conducted by Gupta et al. [4] in Mexico, India, Brazil, and Argentina indicated that 41.8, 22.1, 22, and 19.3\% of children and adolescents are obese in these countries, respectively. Iran is one of the top 7 countries with the highest prevalence of childhood obesity [5]. The study by Jafari et al. [6] reported the prevalence of OW/OB among people under 18 as $5-13.5 \%$ and $3.2-11.9 \%$, respectively. The prevalence of childhood obesity in Iran has increased 2-4 times over the last 3 decades.

The medical and psychosocial complications of childhood obesity and the heavy burden it imposes on society makes control and prevention of childhood obesity a necessity [3]. Childhood obesity leads to increased cholesterol and blood glucose level, apnea, cardiovascular diseases, and high blood pressure. Moreover, obesity in childhood increases the risk of developing diabetes, cancer, premature mortality, and many other physical diseases and complications in adulthood $[7,8]$. Childhood obesity also leads to undesirable psychological consequences like sleep disorders, low self-confidence, anxiety, and depression, affecting the child's social and educational relationships. OW/OB are the fifth major cause of death, causing 2.6 million deaths annually [9-12].

Researchers believe that the increase in the prevalence of $\mathrm{OW} / \mathrm{OB}$ results from the new changes in lifestyles of societies, such as inactivity, disturbed energy balance, increased consumption of animal proteins and fast food, and increased use of technology [13]. Although heredity might predispose people to obesity, inappropriate lifestyle is also a major factor affecting the development of obesity and chronic diseases [14]. Numerous studies conducted on the factors associated with childhood obesity indicated the effective role of parents and family environment in the development of obesity $[15,16]$. Parental obesity, especially the mother's obesity, is among the factors directly associated with the child's obesity in many studies, and it is considered the most important factor associated with childhood obesity [17]. The mother is the closest person to the child and the first person affecting the formation of the child's behavior and lifestyle; therefore, the mother has a major role in determining the child's weight $[18,19]$. A total of $40 \%$ of children one of whose parents are overweight develop obesity, while only $10 \%$ of children none of whose parents are overweight develop such problems [11]. Therefore, the purpose of this research was to determine the knowledge, attitude, and practices (KAP) of Iranian mothers towards childhood OW/OB.

\section{Materials and Methods}

\section{Study Population and Setting}

The present study is a cross-sectional descriptive analysis conducted on 432 mothers with children aged 6-7 years, who were referred to the health centers (5 health centers) of the city of Zarandieh in 2017. The sample size was assessed considering the $95 \%$ confidence level and accuracy of $5 \%$, and the prevalence of childhood obesity was derived from previous similar studies of 380 people $[6,20]$. To increase the research accuracy, 442 questionnaires were distributed, of which 6 of the women were excluded due to informed dissatisfaction, and finally, 436 questionnaires were collected (about 88 questionnaires in each center) by the research team. The sampling method in this study was multistage random sampling. In the first stage, all the health centers of the city ( 5 centers) were selected through census method. 
In the next stage, 88 children ( 44 boys and 44 girls) and their mothers were selected and included in the study through simple random sampling, considering the inclusion criteria and based on family file numbers available in each center. The inclusion criterion was mothers with at least one child aged 6-7 years, while mothers with children suffering from disability and movementdisorders, diagnosed with psychiatric disorders (anorexia, bulimia, depression, bipolar disorders), suffering from chronic diseases, under treatment by certain medications or medications to gain or lose weight (medications, physical, dietary), or unwilling to participate were excluded from the study.

\section{Measures}

The weight and height of all the selected children were measured, and the BMI was then calculated. The height was measured in standing position and without shoes using a standard strip meter with a precision of $0.5 \mathrm{~cm}$, the weight was measured using dial scale (SECA model) with a precision of $0.5 \mathrm{~kg}$, and BMI was calculated by dividing the weight (in kilograms) by the square of the height (in meters squared), the formula being BMI = $\mathrm{kg} / \mathrm{m}^{2}$.

The National Center for Health Statistics/World Health Organization (NCHS/WHO) BMI percentiles were used to determine OW/OB: underweight: $<5$ th BMI-for-age; normal weight: 5 th $<$ BMI-for-age $<85$ th; overweight: 85 th BMI-for-age $<95$ th; and obese: BMI-for-age $\geq 95$ th. In addition, the WHO cut-off percentile classification was used to determine parents' OW/OB: underweight: BMI $<18.5 \mathrm{~kg} / \mathrm{m}^{2}$, normal weight: BMI $18.5-24 \mathrm{~kg} / \mathrm{m}^{2}$; overweight: BMI $25-29$ $\mathrm{kg} / \mathrm{m}^{2}$; obese: $\mathrm{BMI}>30 \mathrm{~kg} / \mathrm{m}^{2}$. The reliability of the scale and the meter used was assessed in three stages using the test-retest method.

\section{Questionnaire}

A multisection questionnaire derived from the previous literature $[1,5,7,14,21]$ was used in this research. It consisted of 4 parts:

1. Demographic and medical characteristics: child's age, gender, present height $(\mathrm{cm})$, present weight (kg), weight at birth, infant feeding, starting age of auxiliary food, birth order, number of children, mother's age, parent education, occupation, parent BMI, and family history of disease.

2. Knowledge: this part included 10 question about the definition, factors, and consequences of obesity; the answers were set as yes/no/I don't know choices; 2 points were assigned to true answers, 1 point to "I don't know," and 0 points to false answers.

3. Attitude: this section included questions for assessing the attitude of mothers towards childhood obesity like "I think obese children are at a higher risk of developing heart problems in adulthood"; the answers were set on a 5-point Likert scale ranging from 1 (strongly disagree) to 5 (strongly agree); higher points indicated a more negative attitude towards obesity; the reliability of this section was determined through Cronbach's $\alpha$ coefficient ( $\alpha=0.84)$.

4. Practices: this section included 16 questions about the practice of children in the fields of nutrition and physical activity, such as fruit and vegetable consumption, junk food and fast food consumption, breakfast consumption, the amount and intensity of physical activity, duration of TV watching/computer games, and rest and sleep patterns; the reliability of this section was determined through Cronbach's $\alpha$ coefficient $(\alpha=0.79)$.

The validity of the demographic characteristics and KAP of the questionnaire was assessed through the content validity method: content validity index (CVI) and content validity ratio (CVR). After preparing and collecting the questionnaires, they were given to 10 
Karimy et al.: Knowledge, Attitude, and Practices of Iranian Mothers towards Childhood OW/OB

Table 1. Distribution of demographic variables according to

\begin{tabular}{|c|c|c|c|}
\hline \multirow[t]{2}{*}{ Variable } & \multicolumn{2}{|l|}{ BMI } & \multirow[t]{2}{*}{$p$} \\
\hline & $\begin{array}{l}\text { normal weight } \\
(n=379)\end{array}$ & obese $(n=53)$ & \\
\hline \multicolumn{4}{|l|}{ Sex } \\
\hline Boys & $181(47.7)$ & $33(62.2)$ & \multirow[t]{2}{*}{0.04} \\
\hline Girls & $198(52.3)$ & $20(37.7)$ & \\
\hline \multicolumn{4}{|l|}{ Mother's BMI } \\
\hline Underweight & $38(10)$ & $3(5.7)$ & \\
\hline Normal & $162(42.7)$ & $12(24.5)$ & \\
\hline Overweight and obese & $179(47)$ & $37(69.8)$ & 0.009 \\
\hline \multicolumn{4}{|l|}{ Birth order } \\
\hline 1 st & $95(25)$ & $25(47)$ & \multirow[t]{3}{*}{0.003} \\
\hline 2nd & $194(51)$ & $18(34)$ & \\
\hline$\geq 3 \mathrm{rd}$ & $90(23.7)$ & $10(18.8)$ & \\
\hline \multicolumn{4}{|l|}{ Birth weight } \\
\hline$<3 \mathrm{~kg}$ & $190(50.1)$ & $18(34)$ & \multirow[t]{2}{*}{0.02} \\
\hline$\geq 3 \mathrm{~kg}$ & 189 (49.9) & $35(66)$ & \\
\hline
\end{tabular}

Data are presented as $n(\%)$. Normal weight: 5 th-85th percentile; overweight and obese: $\geq 85$ th percentile. BMI, body mass index.

experts of health sciences, behavioral sciences, and nutrition, their desired corrections were made, and the CVI and CVR were measured as 81 and 79\%, respectively.

Data collection was conducted by trained instructors after presenting the required letters of reference to the health centers. Having been telephoned and informed about the study objectives, the selected mothers were invited by the instructors to the health centers, and they completed the questionnaires over a 1-h session in a separate room in a self-report method. Also, the height and weight of both the mothers and the children were measured and recorded by the instructors.

\section{Statistical Analysis}

The data were analyzed by SPSS version 18 and using descriptive statistics indexes (frequency distribution) and inferential statistics tests $\left(\chi^{2}\right.$ test, independent $t$ test, variance analysis, and Pearson correlation coefficient).

\section{Results}

\section{Demographic Characteristics and Obesity}

Overall, of the 436 completed questionnaires, 4 were ignored due to being defective, and the result analysis was conducted on 432 questionnaires ( 214 boys and 218 girls). According to BMI results, most of the children $(n=379)$ were in the normal range, while 53 children $(9.2 \%)$ were OB. The prevalence of OB was $11.5 \%$ in boys and $7 \%$ in girls, and this difference was statistically significant $(p<0.05)$. A total of 271 mothers under study were OB. Children with $\mathrm{OB}$ mothers had significantly higher BMI $(p<0.05)$. In addition, mean weight at birth was significantly higher in obese children than in non-obese children $(p<0.05)$. In this study, there was a significant relationship between birth order and childhood obesity: the prevalence of obesity was higher in those who were the first children of families (Table 1). Parent education, mother's age, and family size were not associated with OW/OB children $(p>$ $0.05)$. 
Table 2. Comparison of knowledge and attitude scores towards childhood obesity between mothers according to BMI status

\begin{tabular}{lllll}
\hline Variables & Total & BMI & $p$ \\
\cline { 3 - 4 } & & $\begin{array}{l}\text { normal weight } \\
(n=379)\end{array}$ & obese $(n=53)$ & \\
\hline Knowledge & $15.8 \pm 3.4$ & $16.1 \pm 3.1$ & $15.5 \pm 3.6$ & 0.169 \\
Attitude & $28.2 \pm 7.5$ & $34.6 \pm 6.8$ & $25.2 \pm 7.7$ & 0.001 \\
\hline
\end{tabular}

Data are presented as mean \pm SD. Normal weight: 5 th-85th percentile; overweight and obese: $\geq 85$ th percentile. BMI, body mass index.

\section{Knowledge and Attitude of Mothers towards OB Children}

The mean score of $15.8 \pm 3.4$ out of 20 received by mothers indicated that the population under study had relatively good knowledge. For example, most of the mothers knew about the factors affecting obesity such as inappropriate feeding, fast foods (79\%), inactivity (76\%), and genetics (68\%). Also, 81\% knew about the effect of childhood obesity on adulthood diabetes and hypertension. A total of $46 \%$ of mothers considered industrial fruit juice as a suitable substitute for natural fruit. The independent $t$ test did not show any significant difference in the mean scores for knowledge between mothers with obese children and those with normal-weight children. As regards mothers' attitude towards obesity, the results showed that the mean score for attitude of mothers with normal-weight children was higher than the mean score for those with obese children, and the difference was statistically significant $(p<0.05)$. Here, $21 \%$ of mothers agreed with the phrase "Obese children are healthier," while $58 \%$ believed that childhood obesity is a serious problem. Overall, 39\% of mothers with obese children did not believe their children were obese, and $52 \%$ considered obese children more attractive (Table 2 ).

\section{Practices}

In the nutrition practice section, there was a significant relationship between having breakfast, having fast food at least twice a week, and eating in front of TV with children's BMI, but there was no significant relationship between consumption of carbonated beverages, junk food, sweets, fruit and vegetables, and greasy food with children's BMI. In the physical activity section, there was a significant relationship between the amount of physical activity, sleep, watching TV, and playing computer games with children's OB $(p<0.05)$ (Table 3$)$.

\section{Discussion}

According to the results, $9.2 \%$ of children in the present study were OB. This result is in line with the national study conducted in Iran, which reported the prevalence of $\mathrm{OB}$ to be between 3.2 and 11.9\%. Previous studies conducted around the world and Iran indicated that childhood obesity is epidemic $[6,19,20]$. Considering the numerous medical and psychosocial complications of childhood obesity and the heavy burden it imposes on society, it is necessary to pay attention, control, and prevent childhood obesity. In this study, the prevalence of OW/ OB was significantly higher in boys than in girls. In line with the present study, in the study conducted by Bener [22] and that by Öner et al. [23], the prevalence of obesity was higher in boys than in girls. One of the reasons for this difference is the possibility that more attention is payed to boys in Iranian culture. The greater interest of boys in eating fast foods and playing more computer games might be one of the other reasons behind this difference. 
Karimy et al.: Knowledge, Attitude, and Practices of Iranian Mothers towards Childhood OW/OB

Table 3. Differences in children's behavior according to BMI status

\begin{tabular}{|c|c|c|c|}
\hline \multirow[t]{2}{*}{ Variables } & \multicolumn{2}{|l|}{ BMI } & \multirow[t]{2}{*}{$p$} \\
\hline & $\begin{array}{l}\text { normal weight } \\
(n=379)\end{array}$ & obese $(n=53)$ & \\
\hline \multicolumn{4}{|l|}{ Nutrition } \\
\hline \multicolumn{4}{|c|}{ Consumption of breakfast at least 4 times a week } \\
\hline Yes & $299(78.8)$ & $16(30.2)$ & \multirow[t]{2}{*}{0.001} \\
\hline No & $80(21.2)$ & $37(69.8)$ & \\
\hline \multicolumn{4}{|c|}{ Eating in front of TV } \\
\hline Yes & $226(59.6)$ & $39(73.6)$ & \multirow[t]{2}{*}{0.05} \\
\hline No & $153(40.4)$ & $14(26.4)$ & \\
\hline \multicolumn{4}{|c|}{ Fast foods consumed at least 2 times a week } \\
\hline Yes & $78(20.6)$ & $21(39.6)$ & \multirow{2}{*}{0.002} \\
\hline No & $301(79.4)$ & $32(60.4)$ & \\
\hline \multicolumn{4}{|c|}{ Physical activity } \\
\hline \multicolumn{4}{|c|}{ Watching TV $>3 \mathrm{~h} /$ day } \\
\hline Yes & $210(55.4)$ & $38(71.7)$ & \multirow[t]{2}{*}{0.02} \\
\hline No & $169(44.6)$ & $15(28.3)$ & \\
\hline \multicolumn{4}{|c|}{ Regular physical activity $>3 \mathrm{~h} /$ week } \\
\hline Yes & $275(72.5)$ & $5(9.4)$ & \multirow[t]{2}{*}{0.001} \\
\hline No & $104(27.5)$ & $48(90.6)$ & \\
\hline \multicolumn{4}{|c|}{ Sleep $>9$ h/day } \\
\hline Yes & $257(67.8)$ & $28(52.8)$ & \multirow[t]{2}{*}{0.03} \\
\hline No & $122(32.2)$ & $25(47.2)$ & \\
\hline \multicolumn{4}{|c|}{ Computer games $>2 \mathrm{~h} /$ day } \\
\hline Yes & $69(18.2)$ & $16(30)$ & \multirow[t]{2}{*}{0.04} \\
\hline No & $310(81.8)$ & $37(70)$ & \\
\hline
\end{tabular}

Data are presented as $n(\%)$. Normal weight: 5 th-85th percentile; overweight and obese: $\geq 85$ th percentile. BMI, body mass index.

In the present study, children with obese mothers were at higher risk of developing OW/ OB. This finding was in line with the study by Parikka et al. [15] and Jiménez-Cruz et al. [24]. Similarly, the study by Strauss and Knight [17] showed mothers' obesity to be a major variable affecting childhood obesity. According to the results of another study on American children, mothers' obesity was the most important predictor of childhood obesity, increasing the risk of developing obesity 3.62 times [25]. In the study by Santiago et al. [26], mothers' obesity increased the risk of developing childhood obesity up to 1.5 times. In the study by Lin et al. [27], there was a strong and significant relationship between the mother's BMI and the child's BMI: for each unit increase in the mother's BMI, the child's BMI increased between 0.13 and 0.15 . According to the previous studies, the relationship between the mother's and the child's BMI could be explained based on the following three reasons: the effect of genetics, inappropriate nutrition patterns, and the behavioral patterns of parents on developing obesity $[15,26]$.

The results of the present study show that the weight at birth was significantly higher in obese children than in non-obese children. Studies conducted on Chinese and African children showed a significant relationship between weight at birth and children's BMI $[28,29]$. The relationship between high weight at birth and high risk of developing childhood obesity is attributed to metabolic and endocrine activities during embryonic development $[3,4,12]$. According to the findings, there was a significant relationship between the birth order and the child's BMI, as the prevalence of obesity was higher among the first children of families. This finding is similar to those in the study by Celi et al. [30] on Italian children and the study 
by Dasappa et al. [19] on Indian children. This weight gain could be explained by parents paying more attention to the first children and the more health and nutrition facilities which are consequently provided to the first children.

In this study, no significant difference was observed between the scores for knowledge of mothers with normal BMI and those with obese BMI. This could be justified by the fairly good scores of mothers in the present study. This finding is in line with those of the study by Sayyari et al. [5], which showed that $84.2 \%$ of girls knew about the complications of obesity, and $98.4 \%$ knew about the importance of physical activity and exercise for losing weight. Similar to the previous studies in this field $[18,19]$, the mean score for attitude for mothers with normal BMI was higher than the mean score for those with obese children in the present study. In line with the present findings, the study conducted by Hatta et al. [18] in Malaysia showed that there was a relationship between the attitude towards obesity and nutrition behaviors, while no significant relationship was found between knowledge and practice. Similarly, in the study by Kigaru et al. [31], parents' attitude towards childhood obesity was the most important determinant of childhood obesity. In the present study, there was a relationship between eating habits (consumption of breakfast, consumption of fast food at least twice a week, and eating in front of TV) and children's obesity. This finding was similar to the those in the study by Etelson et al. [32] and the study by Papoutsi et al. [33], which showed that the family's eating habits such as having breakfast, fast food, etc. have an important role in determining the child's BMI. Similarly, the study by Raja'a and Bin Mohanna [34] in Yemen indicated that there is a relationship between using ready-to-eat food and childhood obesity. In another study, Vanhala et al. [35] found that skipping breakfast is a risk factor for developing childhood OW/OB. In the studies by Boyse [10] and Manios et al. [36], the important role of TV in defining the child's BMI and his/her eating habits is emphasized.

In our study there was a relationship between the amount of the child's physical activity and his/her BMI. In line with our findings, the study by Arluk et al. [37] showed that watching TV or playing computer games for more than $2 \mathrm{~h}$ a day increases the risk of developing obesity. Similarly, the study by Dasappa et al. [19] showed that there was a significant relationship between the child's physical activity and his/her BMI. In another study, Vos and Welsh [38] proved that children's physical activity and exercise is a protective factor against obesity.

A few limitations should be considered in the interpretation of the results of this research. First, as this was a cross-sectional study it was limited to identifying association and not causality. Second, recording the behavior of children was based on their mothers' reports.

\section{Conclusion}

According to the results, it seems necessary to develop interventions to improve and modify nutritional functions and create appropriate physical activity habits in children in order to change the beliefs and lifestyles of families with the aim of preventing and overcoming problems such as OB in children. Since modifying behavior requires a change in underlying attitudes, the factor of "attitude" should also be considered in designing such interventions.

\section{Acknowledgments}

The authors of this study gratefully acknowledge the help of the women and children who took part in this study, without whose contribution the present research would not have been completed. We also thank the deputy director of the Public Health Department of Saveh University of Medical Sciences. 


\section{Statement of Ethics}

Ethical considerations were observed in this study by obtaining written consent from the participants, making participation in the study voluntary, making the questionnaires anonymous, and keeping the data confidential. Moreover, the present study had license and code of ethics from the Ethics Committee of Saveh University of Medical Sciences.

\section{Disclosure Statement}

No conflict of interest has been declared by the authors.

\section{Funding Sources}

This work received no specific grant from any funding agency or university in the public, commercial, or other sectors.

\section{Author Contributions}

M.K. conceptualized and designed the study, drafted the manuscript, and approved the final version. N.F. designed the study, collected the data, and approved the final manuscript. B.A. conceptualized and designed the study, drafted the manuscript, and approved the final version.

\section{References}

1 Gies I, AlSaleem B, Olang B, Karima B, Samy G, Husain K, et al. Early childhood obesity: a survey of knowledge and practices of physicians from the Middle East and North Africa. BMC Pediatr. 2017 Apr; 17(1):115.

2 Ward DS, Welker E, Choate A, Henderson KE, Lott M, Tovar A, et al. Strength of obesity prevention interventions in early care and education settings: a systematic review. Prev Med. 2017 Feb;95 Suppl:S37-52.

3 Kelishadi R, Haghdoost AA, Sadeghirad B, Khajehkazemi R. Trend in the prevalence of obesity and overweight among Iranian children and adolescents: a systematic review and meta-analysis. Nutrition. 2014 Apr;30(4): 393-400.

4 Gupta N, Goel K, Shah P, Misra A. Childhood obesity in developing countries: epidemiology, determinants, and prevention. Endocr Rev. 2012 Feb;33(1):48-70.

5 Sayyari AA, Abdollahi Z, Ziaodini H, Olang B, Fallah H, Salehi F, et al. Methodology of the comprehensive program on prevention and control of overweight and obesity in Iranian children and adolescents: the IRANEnding childhood obesity (IRAN-ECHO) program. Int J Prev Med. 2017 Dec;8(1):107.

6 Jafari-Adli S, Jouyandeh Z, Qorbani M, Soroush A, Larijani B, Hasani-Ranjbar S. Prevalence of obesity and overweight in adults and children in Iran; a systematic review. J Diabetes Metab Disord. 2014 Dec;13(1): 121.

7 Martins C, Norsett-Carr A. Obesity Knowledge among Final-Year Medical Students in Norway. Obes Facts. 2017;10(6):545-58.

8 Zhang J, Li X, Hawley N, Zheng Z, Zou Z, Tan L, et al. Trends in the Prevalence of Overweight and Obesity among Chinese School-Age Children and Adolescents from 2010 to 2015. Child Obes. 2018 Apr;14(3):182-8.

9 Speiser PW, Rudolf MC, Anhalt H, Camacho-Hubner C, Chiarelli F, Eliakim A, et al.; Obesity Consensus Working Group. Childhood obesity. J Clin Endocrinol Metab. 2005 Mar;90(3):1871-87.

10 Boyse K. A guide to managing television: tips for your family. University of Michigan: YourChild Development and Behavior Resources; 2009.

11 Kliegman RM, Behrman RE, Jenson HB, Stanton BM. Nelson textbook of pediatrics e-book. Elsevier Health Sciences; 2007.

12 Chen JL, Kennedy C. Factors associated with obesity in Chinese-American children. Pediatr Nurs. 2005 Mar-Apr;31(2):110-5. 
13 Militello LK, Melnyk BM, Hekler E, Small L, Jacobson D. Correlates of healthy lifestyle beliefs and behaviors in parents of overweight or obese preschool children before and after a cognitive behavioral therapy intervention with text messaging. J Pediatr Health Care. 2016 May-Jun;30(3):252-60.

14 Katzmarzyk PT, Barreira TV, Broyles ST, Champagne CM, Chaput JP, Fogelholm M, et al.; ISCOLE Research Group. Relationship between lifestyle behaviors and obesity in children ages 9-11: results from a 12-country study. Obesity (Silver Spring). 2015 Aug;23(8):1696-702.

15 Parikka S, Mäki P, Levälahti E, Lehtinen-Jacks S, Martelin T, Laatikainen T. Associations between parental BMI, socioeconomic factors, family structure and overweight in Finnish children: a path model approach. BMC Public Health. 2015 Mar;15(1):271.

16 Danielzik S, Czerwinski-Mast M, Langnäse K, Dilba B, Müller MJ. Parental overweight, socioeconomic status and high birth weight are the major determinants of overweight and obesity in 5-7 y-old children: baseline data of the Kiel Obesity Prevention Study (KOPS). Int J Obes Relat Metab Disord. 2004 Nov;28(11):1494-502.

17 Strauss RS, Knight J. Influence of the home environment on the development of obesity in children. Pediatrics. 1999 Jun;103(6):e85-85.

18 Hatta NK, Rahman NA, Rahman NI, Haque M. Knowledge, Attitude and practices among mothers regarding childhood obesity at Kuantan, Malaysia. Int Med J. 2017;24(2):200-4.

19 Dasappa H, Fathima FN, Ganesh K, Prasad S. Prevalence, risk factors and attitude of parents towards childhood obesity among school children in Bangalore city. Int J Community Med Public Health. 2018;5(2):749-53.

20 Rahmani A, Sayehmiri K, Asadollahi K, Sarokhani D, Islami F, Sarokhani M. Investigation of the prevalence of obesity in Iran: A systematic review and meta-analysis study. Acta Med Iran. 2015 Oct;53(10):596-607.

21 Vafadar Z, Reazei R, Navidian A. Effectiveness of motivational interviewing on the weight self-efficacy life style in overweight and obese teenager boys. Int J Behav Sci. 2014;8(2):185-93.

22 Bener A. Prevalence of obesity, overweight, and underweight in Qatari adolescents. Food Nutr Bull. 2006 Mar; 27(1):39-45.

23 Öner N, Vatansever Ü, Sari A, Ekuklu G, Güzel A, Karasalihoglu S, Boris NW. Prevalence of underweight, overweight and obesity in Turkish adolescents. Swiss Med Wkly. 2004 Sep 4;134(35-36):529-3.

24 Jiménez-Cruz A, Wojcicki J, Bacardí-Gascón M, Castellón-Zaragoza A, García-Gallardo J, Schwartz N, Heyman MB. Maternal BMI and migration status as predictors of childhood obesity in Mexico. Nutr Hosp. 2011 Jan-Feb; 26(1):187-93.

25 Ishihara T, Takeda Y, Mizutani T, Okamoto M, Koga M, Tamura U, et al. [Relationships between infant lifestyle and adolescent obesity. The Enzan maternal-and-child health longitudinal study]. Nihon Koshu Eisei Zasshi. 2003 Feb;50(2):106-17. Japanese.

26 Santiago S, Zazpe I, Cuervo M, Martínez JA. Perinatal and parental determinants of childhood overweight in 6-12 years old children. Nutr Hosp. 2012 Mar-Apr;27(2):599-605.

27 Lin BH, Huang CL, French SA. Factors associated with women's and children's body mass indices by income status. Int J Obes Relat Metab Disord. 2004 Apr;28(4):536-42.

28 He Q, Ding ZY, Fong DY, Karlberg J. Risk factors of obesity in preschool children in China: a population-based case-control study. Int J Obes Relat Metab Disord. 2000 Nov;24(11):1528-36.

29 Gulliford MC, Mahabir D, Rocke B, Chinn S, Rona R. Overweight, obesity and skinfold thicknesses of children of African or Indian descent in Trinidad and Tobago. Int J Epidemiol. 2001 Oct;30(5):989-98.

30 Celi F, Bini V, De Giorgi G, Molinari D, Faraoni F, Di Stefano G, et al. Epidemiology of overweight and obesity among school children and adolescents in three provinces of central Italy, 1993-2001: study of potential influencing variables. Eur J Clin Nutr. 2003 Sep;57(9):1045-51.

31 Kigaru DM, Loechl C, Moleah T, Macharia-Mutie C, Ndungu ZW. Nutrition knowledge, attitude and practices among urban primary school children in Nairobi City, Kenya: a KAP study. BMC Nutr. 2015;1(1):44.

32 Etelson D, Brand DA, Patrick PA, Shirali A. Childhood obesity: do parents recognize this health risk? Obes Res. 2003 Nov;11(11):1362-8.

33 Papoutsi G, Drichoutis A, Nayga R Jr. The causes of childhood obesity: a survey. J Econ Surv. 2013;27(4):74367.

34 Raja'a YA, Bin Mohanna MA. Overweight and obesity among schoolchildren in Sana'a City, Yemen. Ann Nutr Metab. 2005 Sep-Oct;49(5):342-5.

35 Vanhala M, Korpelainen R, Tapanainen P, Kaikkonen K, Kaikkonen H, Saukkonen T, et al. Lifestyle risk factors for obesity in 7-year-old children. Obes Res Clin Pract. 2009 May;3(2):I-II.

36 Manios Y, Kondaki K, Kourlaba G, Grammatikaki E, Birbilis M, Ioannou E. Television viewing and food habits in toddlers and preschoolers in Greece: the GENESIS study. Eur J Pediatr. 2009 July;168(7):801-8.

37 Arluk SL, Branch JD, Swain DP, Dowling EA. Childhood obesity's relationship to time spent in sedentary behavior. Mil Med. 2003 Jul;168(7):583-6.

38 Vos MB, Welsh J. Childhood obesity: update on predisposing factors and prevention strategies. Curr Gastroenterol Rep. 2010 Aug;12(4):280-7. 